\title{
Studies on the epidemiology and histopathology of Euclinostomum heterostomum (Trematoda; Digenea) infection in Channa punctata from North India
}

\author{
P. A. Ahammed Shareef, Syed M. A. Abidi
}

Received - 01 May 2015/Accepted - 08 September 2015. Published online: 31 October 2015; @Inland Fisheries Institute in Olsztyn, Poland Citation: Shareef P.A.A., Abidi S.M.A. 2015 - Studies on the epidemiology and histopathology of Euclinostomum heterostomum (Trematoda; Digenea) infection in Channa punctata from North India - Arch. Pol. Fish. 23: 133-140.

\begin{abstract}
A survey on the occurrence and epidemiology of the encysted progenetic metacercariae of Euclinostomum heterostomum infection in Channa punctata in the Aligarh region of North India revealed a mean prevalence, intensity, and abundance of $18.61,1.52$, and $0.38 \%$, respectively, during the period from April 2011 to March 2012. Liver, kidney, peritoneum, muscle, and ovary were found to be infected with this parasite, and the later three are reported for the first time in this fish species. The histopathology of the infected tissues indicated the following at the host-parasite interface: tissue damage, infiltration of immune cells into the cyst wall, chronic inflammatory responses, and granulomatous lesions. The infected liver showed degeneration of hepatocytes, cytoplasmic vacuolation, nuclear alterations, mallory body formation, fibrosis, and necrosis. The pathology of the infected kidney included distortion and dilation of renal tubules, vacuolar degeneration, hypertrophy and hyperplasia of tubular epithelial cells, occlusion of tubules, fibrosis, hemorrhage, and congestion of glomeruli. The infected muscle demonstrated comparatively fewer pathological changes confined only to the circumference of the cyst wall. The ovary displayed the least changes. The conclusions drawn from the study are that the large metacercarial cysts formed by E. heterostomum in the vital organs of the economically important fish $C$. punctata could result in the impairment of fish physiology and health, thereby
\end{abstract}

\footnotetext{
P.A.A. Shareef [ $\left.\Xi^{\circ}\right]$, S.M.A. Abidi

Section of Parasitology, Department of Zoology

Faculty of Life Sciences, Aligarh Muslim University

Aligarh, 202 002, U. P., India

e-mail: shareefkpr@gmail.com
}

affecting their productivity and quality for human consumption.

Keywords: incidence, Euclinostomum heterostomum, Channa punctata, histopathology, epidemiology, parasitic infection

\section{Introduction}

Aquaculture is a rapidly growing sector worldwide, and India it is the second largest producer of the same with an annual production of 312.8 million tonnes (FAO 2008). However, health-related problems are an important limiting factor, and parasitic infections are one of the leading constraints of aquaculture production, both qualitatively as well as quantitatively (Scholz 1999). The snake heads, also known as murrels, belonging to the family channidae, constitute the dominant group of air breathing fresh water fishes in terms of both culture and capture fisheries in south and southeast Asian countries where they are regarded as high demand food fish (Wee and Tacon 1982, Haniffa and Mydeen 2011). The spotted murrel, Channa punctata (Bloch), is regarded as a delicious food fish in India (Shareef and Abidi 2012). 
Among the parasites, trematodes are the dominant group that causes retarded growth, morbidity, and mortality especially in juvenile fishes. It has been estimated that about 30000 species of helminths are parasites of fishes (Williams and Jones 1994). In addition to the huge economic loss they cause, at least 50 species of these helminths are potentially zoonotic (Deardorff 1991). The hemophagic clinostomid trematode Euclinostomum heterostomum (Rudolphi 1809) is a common parasite of piscivorous birds in many regions of Asia, Africa, and Europe (Yamaguti 1971). In the Indian subcontinent, the larval stage of this parasite usually infects the liver and kidney of the second intermediate host fish C. punctata as encysted progenetic metacercariae (Jhansilakshmibai and Madhavi 1997). The extent and seasonal variability of their infection have not been reported from North India or elsewhere. Therefore, aim of the present study was to survey the incidence and epidemiology of this parasite in the Aligarh region of North India.

Histological studies of various pathogenic agents in different fish species have been reported and proposed as an efficient method to asses fish health, such as chemicals and pesticides (Altinok and Capkin 2007, Butchiram et al. 2009, Camargo and Martinez 2007, Kelly and Janz 2009, Troncoso et al. 2011), bacteria (Gudmundsdóttir et al. 2006), and helminth parasites (Sanil et al. 2011, Shareef and Abidi 2012). Apart from the lifecycle and morphometry elucidated by some researchers, no study has been found that reports on the host-parasite interaction and the pathogenicity and damage exerted on the tissues of $C$. punctata during infection with E. heterostomum. However, Shareef and Abidi (2012) reported on the histopathological alterations induced by another clinostomid trematode, Clinostomum complanatum, in the same fish. Therefore, the present study attempted to identify the histopathological changes exerted by the parasite on its fish host. We hypothesized that the encystment of such a big parasite in the liver and kidney would result in histopathological lesions as previously reported for pesticides and other chemicals in the same fish (Butchiram et al. 2009).

\section{Materials and Methods}

\section{Examination of fishes for parasitic infection}

Live $C$. punctata from the size group 7-16 $\mathrm{cm}$ were brought from the local fish market of Aligarh (latitude: $27^{\circ} 54^{\prime} \mathrm{N}$; longitude: $78^{\circ} 05^{\prime} \mathrm{E}$ ), North India and transported to the lab in water containers monthly for one year between April 2011 to March 2012. They were maintained in aquaria, but dissected within three days, and the body surface, gills, peritoneal cavity, and all internal organs were examined for $E$. heterostomum infection. The organ/tissue infection was systematically recorded and the prevalence, intensity, and abundance were calculated using standard formula separately for each month throughout the study period. The encysted progenetic metacercariae of $E$. heterostomum were freed from the host tissue and mechanically excysted in $0.74 \% \mathrm{NaCl}$ by carefully tearing up the cyst wall using forceps and needle to liberate the worms, which were processed to prepare permanent slides after staining in carmine for microscopic observations.

\section{Histopathology}

Liver, kidney, muscle, and ovary from C. punctata infected with the encysted progenetic metacercariae of E. heterostomum and uninfected tissue samples were washed quickly in $0.74 \% \mathrm{NaCl}$ and immediately fixed in $10 \%$ neutral buffered formalin for 48 hours, then dehydrated in ascending grades of ethanol, cleared in xylene, and embedded in paraffin wax to cut 5-7 $\mu \mathrm{m}$ thick sections using a rotatory microtome. The sections were stained with hematoxylin and eosin, and permanently mounted slides were prepared. The gross pathology was studied and photographed under a light microscope (Zeiss Axioscope A1), and photographs of the whole mounts were taken with a zoom stereomicroscope (Nikon SMZ 1500). 


\section{Results}

\section{Epidemiology}

The examination of the infected fish viscera showed white or brown round cysts $(2-4 \mathrm{~mm})$ present in liver (Fig. 1A), kidney (Fig. 1B), peritoneal membrane, ovary, and muscles. The later three sites are being reported for the first time in this fish species. The microscopic observation of the prepared permanent slides of mechanically excysted whole worms confirmed that the encysted progenetic metacercaria was E. heterostomum. During the present study period, the prevalence of infection varied considerably from month to month, which is summarized in Table 1. The number of metacercariae per infected fish ranged from 1 to 16 . Furthermore, the liver was found to be the most preferred site of infection, followed by the kidney, while the peritoneal membrane, ovary, and muscle appeared to be occasionally infected. The distribution of infection is presented by organ in Figure 2.

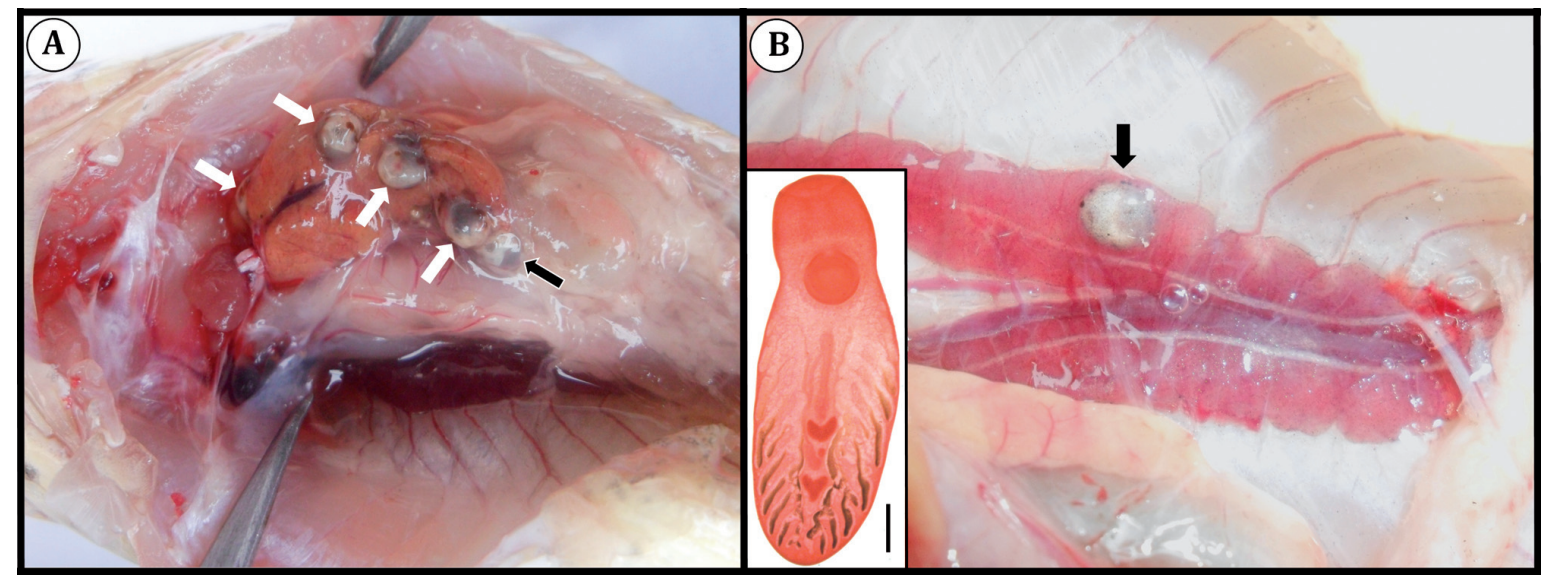

Figure 1. Dissected C. punctata showing the encysted progenetic metacercariae of E. heterostomum in liver (white arrows) and peritoneal membrane (black arrow) (A), and kidney (arrow) (B) and inset - excysted worm (scale $1.0 \mathrm{~mm}$ ).

Table 1

Summary of the epidemiological study of E. heterostomum infection in C. punctata during April 2011 - March 2012

\begin{tabular}{llllllllllll}
\hline \hline Months & $\begin{array}{l}\text { No. of fish } \\
\text { dissected }\end{array}$ & $\begin{array}{l}\text { No. of in- } \\
\text { fected fish }\end{array}$ & $\begin{array}{l}\text { Prevalence of } \\
\text { infection (\%) }\end{array}$ & $\begin{array}{l}\text { No. of cysts } \\
\text { recovered }\end{array}$ & $\begin{array}{l}\text { Range } \\
\text { of cysts }\end{array}$ & Liver & Kidney & Peritoneum & $\begin{array}{l}\text { Muscle } \\
\text { intensity }\end{array}$ & $\begin{array}{l}\text { Abun- } \\
\text { dance }\end{array}$ \\
\hline \hline April & 65 & 24 & 36.92 & 49 & 8 & 39 & 4 & 3 & 3 & 2.04 & 0.753 \\
May & 69 & 23 & 33.33 & 35 & 6 & 26 & 4 & 3 & 2 & 0.65 & 0.507 \\
June & 27 & 11 & 40.74 & 40 & 16 & 35 & 2 & 1 & 2 & 3.63 & 1.481 \\
July & 37 & 3 & 8.10 & 3 & 1 & 3 & 0 & 0 & 0 & 1.00 & 0.081 \\
August & 28 & 2 & 7.14 & 3 & 2 & 3 & 0 & 0 & 0 & 1.50 & 0.107 \\
September & 26 & 3 & 11.53 & 4 & 2 & 3 & 1 & 0 & 0 & 1.33 & 0.153 \\
October & 41 & 1 & 2.43 & 1 & 1 & 1 & 0 & 0 & 0 & 1.00 & 0.024 \\
November & 26 & 4 & 15.38 & 5 & 2 & 4 & 1 & 0 & 0 & 1.25 & 0.192 \\
December & 39 & 0 & 0.00 & 0 & 0 & 0 & 0 & 0 & 0 & 0.00 & 0.000 \\
January & 52 & 7 & 13.46 & 12 & 4 & 10 & 1 & 1 & 0 & 1.71 & 0.230 \\
February & 28 & 6 & 21.42 & 12 & 4 & 11 & 1 & 0 & 0 & 2.00 & 0.428 \\
March & 21 & 7 & 33.33 & 15 & 4 & 10 & 2 & 2 & 1 & 2.14 & 0.714 \\
Total & 459 & 91 & 18.61 & 179 & 4.16 & 145 & 16 & 10 & 8 & 1.52 & 0.389 \\
\hline \hline
\end{tabular}




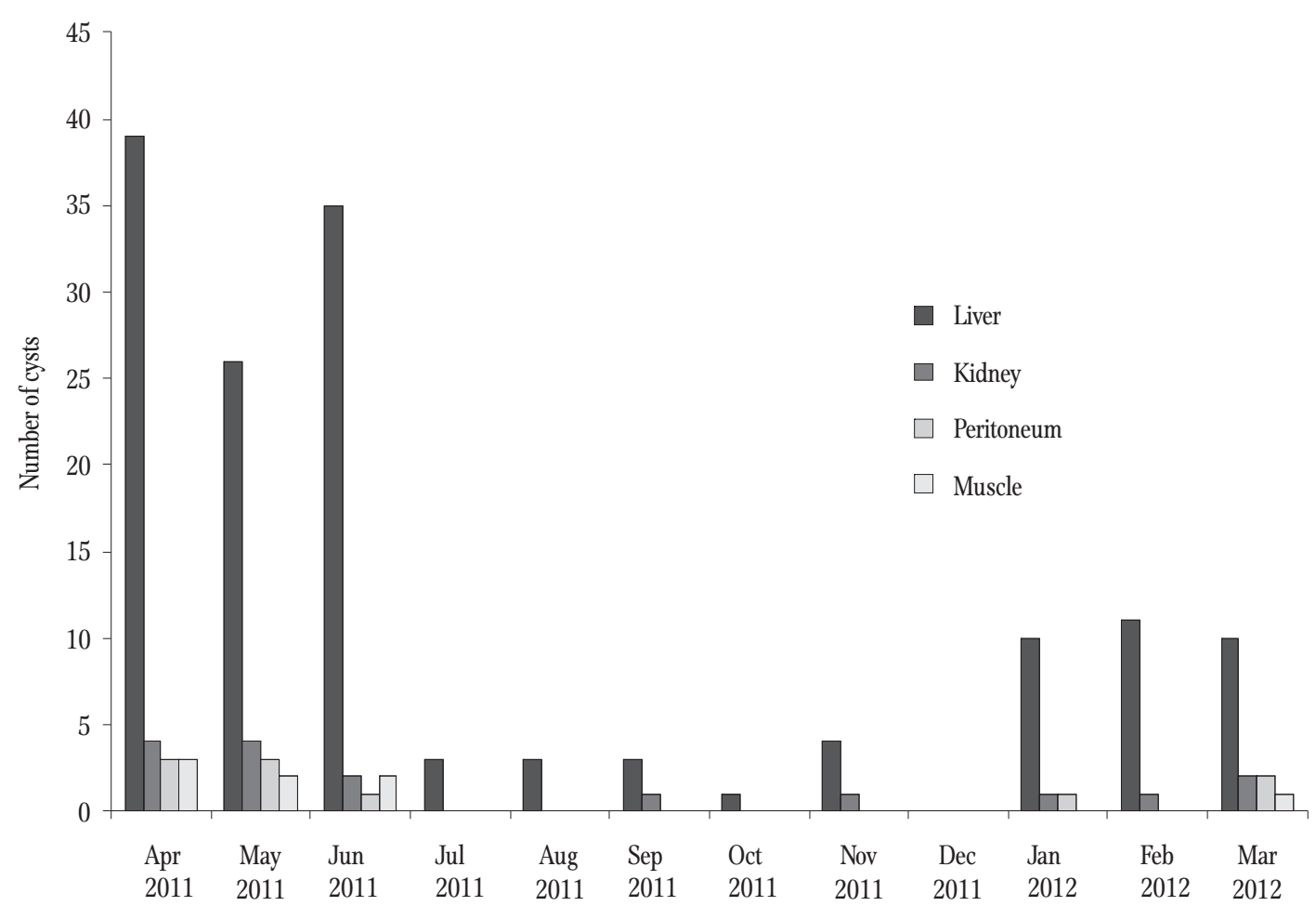

Figure 2. Incidence of encysted progenetic metacercariae of E. heterostomum in different organs of C. punctata during April 2011-March 2012.

\section{Histopathology}

The histology of the infected organs showed that the parasite was surrounded by a thick fibrous capsule of cyst wall. This resulted in the formation of granulomas and the loss of a large functional part of these vital organs. The presence of extracorporeally digested host blood found inside the cyst and within the caecae of the worms is a clear indication of the hemophagic nature of this parasite regardless of the tissue/organ of infection.

\section{Liver}

Infected livers showed high degrees of pathological lesions (Fig. 3). Considerable degeneration of parenchymal hepatocytes, cytoplasmic vacuolation, nuclear alterations, generation of fatty droplets, mallory body formation, individualization of hepatocytes, fibrosis, and necrosis were found. The presence of intense leucocyte infiltration, particularly of eosinophils and macrophages, throughout the cyst wall and in the surrounding tissue is clear evidence of host immune response to the parasite infection. However, this was restricted to the adjoining areas of the cyst, while the remaining parts appeared normal.

\section{Kidney}

The encystment resulted in the loss of a large portions of kidney tissue (Fig. 4). The pathology consisted of fibrosis, distortion and dilation of renal tubules, hypertrophy and hyperplasia of tubular epithelial cells, vacuolar degeneration, occlusion of tubules, congestion of glomeruli, and hemorrhages of interstitial hematopoietic tissue. The host immune response was similar to that of the liver and was limited to the nearby area.

\section{Muscle}

In comparison to the liver and kidney, the infected muscle showed fewer pathological changes. The infiltration of immune cells and the inflammatory response appeared to be somewhat similar to that of other infection sites, but were evident to a lesser 


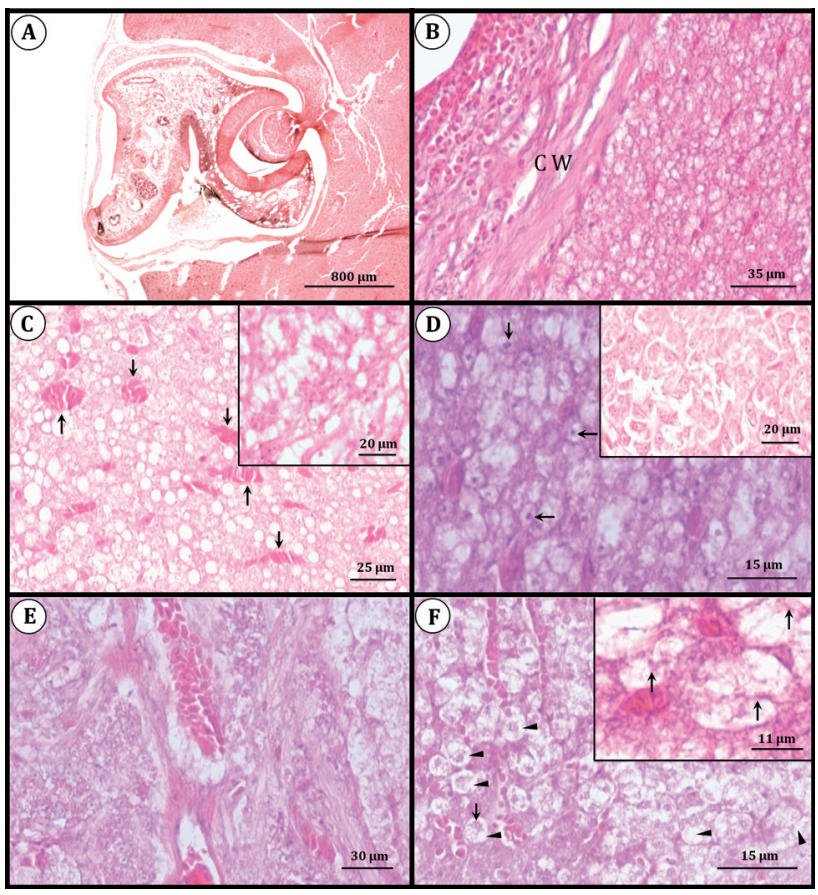

Figure 3. Histopathology of liver infected with E. heterostomum; A - section of liver showing the encysted fluke, enclosed within the cyst wall. Note the tissue damage, the plug formed by the suction of the parasite's ventral sucker, and the ingested host blood (brownish black debris); B - cyst wall (CW) showing the heavy infiltration of immune cells; $\mathrm{C}$ - infected liver showing numerous fatty droplets and hemorrhagic foci (arrow), inset necrosis of hepatocytes; D - infected liver parenchyma showing normal nucleus (arrows), but lacking in most of the cells, insetindividualization of hepatocytes; E - fibrosis; F - cytoplasmic degeneration (arrow head) and nucleus (arrow), inset - Mallory body formation (arrow).

extent and confined to the juxtaposing areas of the cysts only (Fig. 5A).

\section{Ovary}

Unlike other tissues, the infected ovary showed the least visible pathological alterations and no leucocyte infiltration, even in the cyst wall, was observed; however, the eggs lying around the cyst were found to be slightly damaged (Fig. 5B).

\section{Discussion}

Fish health assessment is a tedious, challenging task, and the results obtained are generally not very

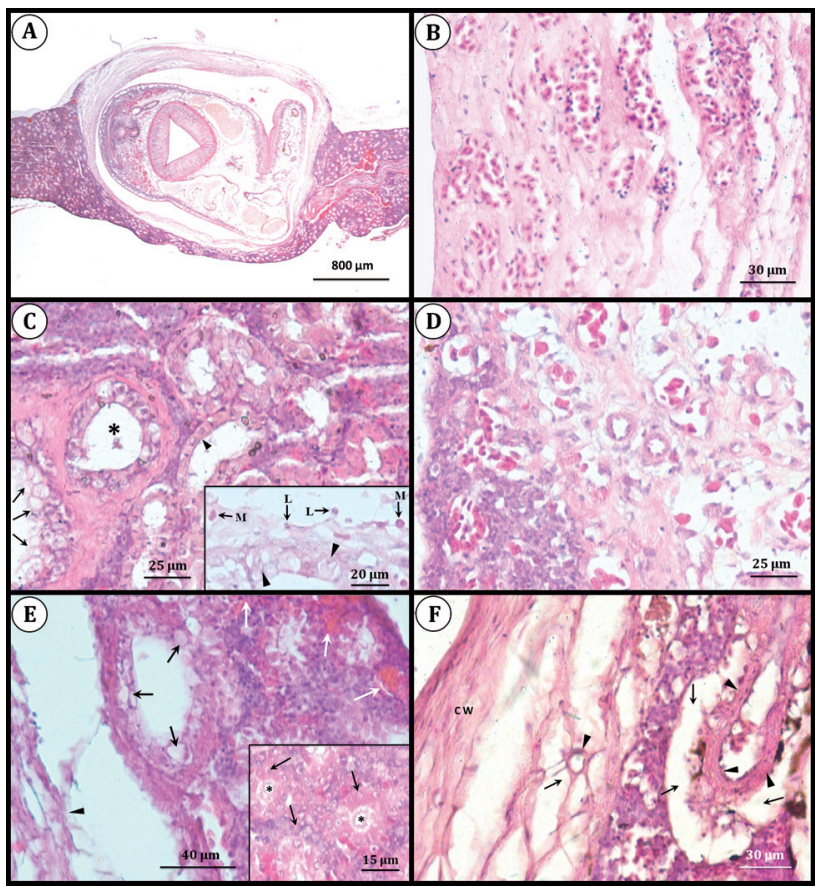

Figure 4. Histopathology of $E$. heterostomum infected kidney of $C$. punctata; A - section of kidney showing the encysted fluke, enclosed within the cyst wall, note the loss of a large portion from the kidney and the worm's oral sucker, pharynx, ventral sucker, and gut are clearly seen; B - enlarged view of cyst wall, note the thickness and heavy infiltration of immune cells; C - renal tubular damage showing the thinning of tubular epithelium (arrow head), abnormally widened lumen (asterisk) and hypertrophy of some epithelial cells, and hyperplasia of tubular epithelial cells (arrow), hyperplasia and hypertrophy of tubular epithelium (arrow head), M - monocytes and L - lymphocytes infiltrated through the cyst wall; D - fibrosis of kidney tubules; E - wall (arrow head), tubule with dilated lumen and hypertrophy of epithelial cells (black arrow), hemorrhage (white arrow), inset occlusion of tubule (asterisk) hypertrophied nucleus (black arrow), and pyknotic nucleus (white arrow); F - fibrosis of tubular epithelium (arrow head), necrosis of epithelial cells resulted in the formation of large vacuole (arrow) and cyst wall (CW).

reliable for many reasons (Kori-Siakpere et al. 2005); therefore, a multidimensional approach is always advisable for a true analysis to establish health and disease condition, rather than any single approach. Histopathology together with the epidemiology can provide more accurate, reliable, meaningful conclusions regarding fish health status along with the ecological factors of a particular aquatic ecosystem in a region. The present study attempted to perform such an integrated, comprehensive assessment of the 


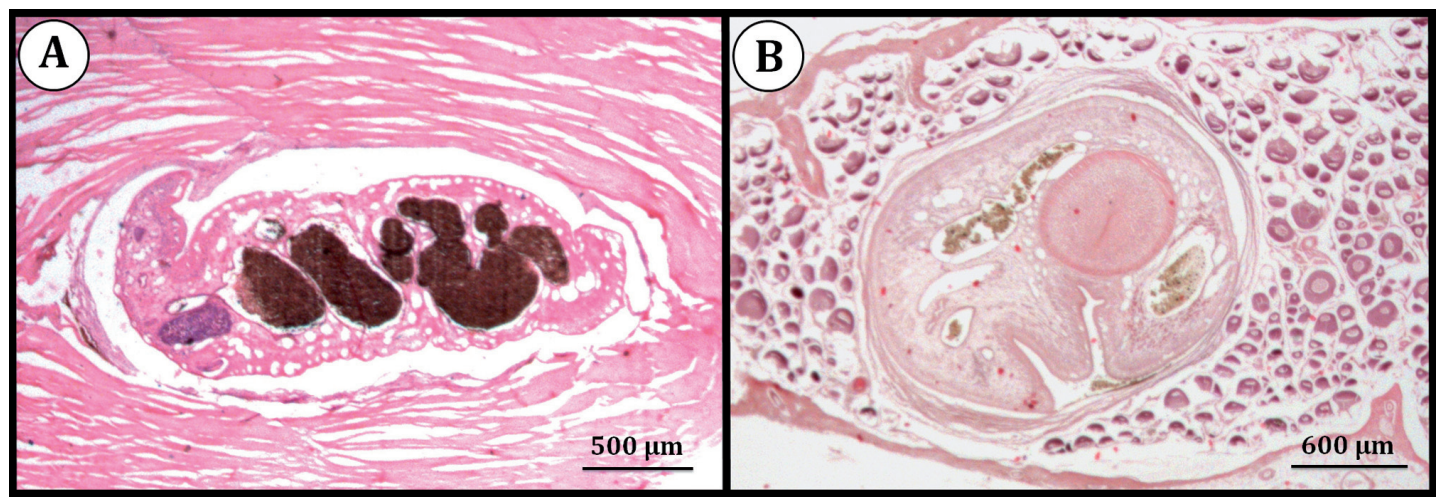

Figure 5. Section showing E. heterostomum encysted in the muscle (A) and ovary (B) of C. punctata. Ingested host blood appears brownish or black within the gut of the worm, a comparatively thin cyst wall, and some damage to muscle fibers are evident.

health of $C$. punctata during infection with the digenean E. heterostomum.

Digenetic trematodes exhibit a complex life cycle. In India, the freshwater snail Indoplanorbis exustus and the fish Channa spp. serve as first and second intermediate hosts respectively, and ardeid birds are the definitive hosts for E. heterostomum. According to Jhansilakshmibai and Madhavi (1997), $E$. heterostomum infect the liver and kidney of $C$. punctata and the muscle of Channa orientalis Bloch\&Schneider. However, it was observed during the present study that this parasite encysts the liver, kidney, peritoneal membrane, ovary, and muscle of C. punctata. Nevertheless, in comparison to other tissues, the liver was found to be the most preferred organ for encystment, possibly because of its large size, particular position, and extensive vascular supply (Van der Oost et al. 2003) that maintains a surplus of nutrients and continuously removes and detoxifies the parasite excretory and/or secretory products.

Studies on the incidence and seasonal variability of parasitic infections would enable farmers and culturists to identify how frequent and to what extent infection is prevailing in a region, so that local management strategies and control measures can be formulated. The epidemiological study of $E$. heterostomum revealed a prevalence rate of $18.61 \%$ and an average of 1.96 cysts per infected fish. Jhansilakshmibai and Madhavi (1997) reported an infection rate of up to $32.7 \%$, harboring up to 66 metacercariae in natural infections and 72 in experimental infections. Whereas, during the present study period, a maximum of 16 cysts per infected fish was recorded. The maximum number of cysts observed in the liver, kidney, peritoneum, and muscle was 13, 2, 2 , and 3 , respectively. It has been elucidated that the parasite takes two months or more to release the infective cercariae from the snails and at least another two months to become encysted metacercaria in this fish (Jhansilakshmibai and Madhavi 1997). The highest prevalence (40.74\%), intensity (3.63), and abundance (1.48) were observed during June, which could stem from higher virulence and favorable weather conditions during the post-winter months when the environmental temperature ranges between 20 to $30^{\circ} \mathrm{C}$. The low incidence during the months following the extreme summer, when the temperature rises to $48^{\circ} \mathrm{C}$, could be from the reduced infectivity of larvae. Furthermore, the monsoon rain and snail availability might also play an important role in varied incidence during different months or seasons. The $0 \%$ prevalence during December could have been from the unavailability of larval stages in the aquatic ecosystem as a consequence of prior heavy rain in North India during July-August 2011 when they might have been carried away with flood waters. This suggests that ecological and climatological factors could also play an important role in the occurrence and distribution of natural infections of this parasite.

Histopathological analysis is a powerful tool to corroborate the histoarchitecture of various tissues during parasitic infections (Eiras et al. 1999, Ferguson 2006, Shareef and Abidi 2012). The results of the present study manifest the pathological alterations 
induced by the digenean parasite $E$. heterostomum on the infected tissue of $C$. punctata. The liver is a biochemical, metabolic center where detoxification, biosynthesis, and biotransformation processes are continuous. Hence, any factor that affects normal functioning would ultimately result in altered physiology causing stress to the fish. The histopathological evidence of this assumption is well established in a number of fish species (Poole and Dick 1984, Camargo and Martinez 2007, Mohamed et al. 2009, Troncoso et al. 2011, Velisek et al. 2009). Butchiram et al. (2009) reported that the liver of C. punctata exposed to alachlor showed cytoplasmic degeneration of hepatocytes, atrophy, formation of vacuoles, rupture of blood vessels, and necrosis. Similar pathology appeared to have occurred in C. punctata as a result of the parasite infection. The prolonged feeding of these flukes might deplete host nutrients and alter normal physiology, as is evident in the results of the hematological study, which can be attributed to retarded growth and reproduction. Additionally, this infection can be fatal in juvenile fishes, which in turn may result in huge economic loss to farmers (Jhansilakshmibai and Madhavi 1997).

The teleostean kidney takes part in excretion, osmoregulation, and hemopoiesis (Butchiram et al. 2009); therefore, its parasitic infection affects normal functions. Butchiram et al. (2009) report similar pathological changes in the kidney of $C$. punctata when exposed to alachlor. Many researchers have reported histopathological studies on many other fish species (Altinok and Capkin 2007, Kelly and Janz 2009, Mohamed 2009). The presence of dilated tubules appears to be a consequence of dead and dying epithelial cells that might affect the reabsorption of ions and nutrients, and the thickening of bowman's capsule can arise as a result of fibrosis, which can interfere with excretion processes (Weber et al. 2003, Kelly and Janz 2009). Furthermore, renal tubule necrosis affects normal functioning and promotes metabolic abnormalities (Yokote 1982, Mohamed 2009). The fibrotic layer of cyst wall was found to be comparatively thicker than those in liver, probably resulting from a strong host immune response.
Muscle is the consumable part of fish, and the presence of parasitic cysts certainly degrades its quality and reduces the price and consumer demand for fish (Silva-Souza and Ludwig 2005). Although the muscles were not severely affected by $E$. heterostomum infection, the consumption of raw or pickled fish could be a potential hazard for the consumer because of the fact that another closely related species, C. complanatum, displays high levels of zoonotic potential. Nevertheless, leucocyte infiltration all around and in the cyst wall was observed in the infected muscle. Eiras et al. (1999) described the histopathology of Loricariichthys platymetopon infected with another clinostomid trematode, Clinostomum marginatum, where the cyst wall was relatively thin and some isolated destruction of surrounding muscle and fat tissue were noted.

Helminth parasite infection can cause reduced energy investment and reproductive potential, decreased number and size of eggs, and lowered fecundity (Heins and Baker 2003, Schults et al. 2006). In the present study, diminished fecundity was evident since the infection caused loss of considerable portions of the ovary. However, the viability of eggs in the infected ovary is not known, and further studies have to be conducted. It was concluded that $E$. heterostomum infection in C. punctata displays considerable seasonal variations as evident from the survey of natural infections. Metacercarial encystation caused substantial tissue damage in most of the vital organs, with liver as the preferred site of infection. It is a paradox that a country positioned at number two in aquaculture production, has performed comparatively fewer, isolated studies on a limited number of fish species infected with parasitic helminths, which necessitates intensifying health and disease studies and documenting them properly.

Acknowledgements. The authors wish to thank the Chairman, Department of Zoology, A.M.U., for providing laboratory facilities. The technical assistance of Mr. Sarfaraz and Mr. Azam, and the Ph.D. studentship provided by Aligarh Muslim University (UGC NON-NET Fellowship, 09-PHD-L-128) are also gratefully acknowledged. 
Author contribution. P.A.A.S. and S.M.A.A. designed research, P.A.A.S. performed research, P.A.A.S. and S.M.A.A. wrote the paper.

\section{References}

Altinok I., Capkin E. 2007 - Histopathology of rainbow trout exposed to sublethal concentrations of methiocarb or endosulfan - Toxicol. Pathol. 35: 405-410.

Butchiram M.S., Tilak K.S., Raju P.W. 2009 - Studies on histopathological changes in the gill, liver and kidney of Channa punctatus (Bloch) exposed to Alachlor - J. Environ. Biol. 30: 303-306.

Camargo M.M.P., Martinez C.B.R. 2007 - Histopathology of gills, kidney and liver of a neotropical fish caged in an urban stream - Neotrop. Ichthyol. 5: 327-336.

Deardoeff T.L. 1991 - Epidemiology of marine fish-borne parasitic zoonoses - Southeast Asian J. Trop. Med. Public Health. 22: 146-149.

Eiras J.C., Dias M.L.G.G., Pavanelli G.C., Machado M.H. 1999 - Histological studies on the effects of Clinostomum marginatum (Digenea, Clinostomidae) in its second intermediate host Loricarichthys platymetopon (Osteichthyes, Loricariidae) of the upper Paraná River, Brazil - Acta Scientiarum 21: 237-241.

Ferguson H.W. 2006 - Systemic pathology of fish. A text and atlas of normal tissues in teleosts and their responses in disease, second ed. - Scotian Press, UK.

FAO 2008 - FAOSTAT Online Statistical Service - United Nations Food and Agriculture Organization (FAO), Rome, available from: http://faostat.fao.org.

Gudmundsdóttir B.K., Björnsdóttir B., Gudmundsdóttir S., Bambir S.H. 2006 - A comparative study of susceptibility and induced pathology of cod, Gadus morhua (L.) and halibut, Hippoglossus hippoglossus (L.), following experimental infection with Moritella viscosa - J. Fish Dis. 29: 481-487.

Haniffa M.A., Mydeen A.K. 2011 - Hematological Changes in Channa striatus Experimentally Infected by Aeromonas hydrophila - Biores. Bull. 4: 246-253.

Heins D.C., Baker J.A. 2003 - Reduction of egg size in natural populations of threespine stickleback infected with a cestode macroparasite - J. Parasitol. 89: 1-6.

Jhansilakshmibai K., Madhavi R. 1997 - Euclinostomum heterostomum (Rudolphi, 1809) (Trematoda): life-cycle, growth and development of the metacercaria and adult Syst. Parasitol. 38: 51-64.

Kelly J.M., Janz D.M. 2009 - Assessment of oxidative stress and histopathology in juvenile northern pike (Esox lucius) inhabiting lakes downstream of a uranium mill Aquat. Toxicol. 92: 240-249.

Kori-Siakpere O., Ake J.E.G., Idoge E. 2005 - Haematological characteristics of the African snakehead, Parachanna obscura - Afr. J. Biotechnol. 4: 527-530.
Mohamed F.A.S. 2009 - Histopathological Studies on Tilapia zillii and Solea vulgaris from Lake Qarun, Egypt - World. J. Fish. Mar. Sci. 1: 29-39.

Poole B.C., Dick T.A. 1984 - Liver pathology of yellow perch, Perca flavescens (Mitchill), infected with larvae of the nematode Raphidascaris acus (Bloch, 1979) - J. Wildl. Dis. 20: 303-307.

Sanil N., Asokan P.K., John L., Vijayan K.K. 2011 - Pathological manifestations of the acanthocephalan parasite, Tenuiproboscis sp. in the mangrove red snapper (Lutjanus argentimaculatus) (Forsskål, 1775), a candidate species for aquaculture from Southern India Aquaculture 310: 259-266.

Scholz T. 1999 - Parasites in cultured and feral fish - Vet. Parasitol. 84: 317-335.

Schultz E.T., Topper M., Heins D.C. 2006 - Decreased reproductive investment of female threespine stickleback Gasterosteus aculeatus infected with the cestode Schistocephalus solidus: parasite adaptation, host adaptation, or side effect? - Oikos. 114: 303-310.

Shareef P.A.A., Abidi S.M.A. 2012 - Incidence and histopathology of encysted progenetic metacercaria of Clinostomum complanatum (Digenea: Clinostomidae) in Channa punctatus and its development in experimental host - Asian. Pac. J. Trop. Biomed. 2: 421-426.

Silva-Souza A.T., Ludwig G. 2005 - Parasitism of Cichlasoma paranaense Kullander, 1983 and Gymnotus carapo Linnaeus, 1814 by Clinostomum complanatum (Rudolphi, 1814) metacercariae in the Taquari River Braz. J. Biol. 65: 513-519.

Troncoso I.C., Cazenave J., Bacchetta C., Bistoni M.A. 2012 Histopathological changes in the gills and liver of Prochilodus lineatus from the Salado River basin (Santa Fe, Argentina) - Fish Physiol. Biochem. 38: 693-702.

Van der Oost R.V., Beyer J., Vermeulen N.P.E. 2003 - Fish bioaccumulation and biomarkers in environmental risk assessment: a review - Environ. Toxicol. Pharmacol. 13: 57-149.

Velisek J., Svobodova Z., Machova J. 2009 - Effects of bifenthrinu on some haematological, biochemical and histopathological parameters of common carp (Cyprinus carpio L.) - Fish Physiol. Biochem. 35: 583-590.

Weber L.P., Higgins P.S., Carlson R.I., Janz D.M. 2003 Development and validation of methods for measuring multiple biochemical indices of condition in juvenile fishes - J. Fish Biol. 63: 637-658.

Wee K.L., Tacon A.G.J. 1982 - A preliminary study on the dietary protein requirement of juvenile snakehead - Bull. Jpn. Soc. Sci. Fish. 48: 1463-1468.

Williams H., Jones A. 1994 - Parasitic worms of fish - Taylor \& Francis, London.

Yamaguti S. 1971 - Synopsis of digenetic trematodes of vertebrates. Vol. 1 - Keigaku Publishing Company, Tokyo, p. 1074.

Yokote M. 1982 - Digestive system - In: An Atlas of Fish Histology (Ed.) T. Hibiya, Normal and Pathological Feature, Kodanshan Ltd, Tokyo, 74-93. 